\title{
Evaluation of Socio-economic Impacts of Incidents on the Railway Infrastructure
}

\author{
Vít Hromádka $^{1}$, Jana Korytárová ${ }^{2}$, Eva Vítková $^{3}$, Tomáš Funk ${ }^{4}$ and Herbert Seelmann ${ }^{5}$ \\ ${ }^{1}$ Brno University of Technology, Faculty of Civil Engineering, Veveří 331/95, 60200 Brno, Czech \\ Republic, hromadka.v@fce.vutbr.cz \\ ${ }^{2}$ Brno University of Technology, Faculty of Civil Engineering, Veveř́ 331/95, 60200 Brno, Czech \\ Republic, korytarova.j@fce.vutbr.cz \\ ${ }^{3}$ Brno University of Technology, Faculty of Civil Engineering, Veveří 331/95, 60200 Brno, Czech \\ Republic, vitkova.e@fce.vutbr.cz \\ ${ }^{4}$ Brno University of Technology, Faculty of Civil Engineering, Veveří 331/95, 60200 Brno, Czech \\ Republic, funk.t@fce.vutbr.cz \\ ${ }^{5}$ Brno University of Technology, Faculty of Civil Engineering, Veveř́ 331/95, 60200 Brno, Czech \\ Republic, seelmann.h@fce.vutbr.cz
}

\begin{abstract}
Evaluation of the economic efficiency of investment projects in transport infrastructure in the Czech Republic is methodically based on the Departmental Methodology of the Ministry of Transport. Economic cash flows, generated in accordance with the CBA principles, are modelled within this methodology on the basis of the evaluation of socio-economic impact of individual projects. In the case of the railway infrastructure constructions, the socio-economic impacts used by the methodology do not include benefits associated with increasing safety and reliability of the railway infrastructure network due to new security systems implementation. Determination of socio-economic impacts associated with specific types of incidents on the railway which are caused by insufficient railway infrastructure security and which could be eliminated by the implementation of the higher-level signaling equipment forms the subject of the research. The research is based on the analysis of a database of incidents occurring on the railway in the Czech Republic in the 2009 - 2018 period, which describes the basic impacts associated with a particular incident. Statistical data on the railway infrastructure is also used to determine the impact of incidents in addition to the database. The key outcomes of the research are the determination of methodological steps for the evaluation of the impacts of incidents on the railway and a case study for their verification. Future research will focus on making evaluation of the abovementioned benefits more detailed. Research outcomes will improve decision-making process on selection and financing of the projects related to railway infrastructure safety for their future implementation.
\end{abstract}

Keywords: Socio-Economic Impacts, Investment Project, Railways, Incidents, Evaluation.

\section{Introduction}

The paper focuses on presentation of partial results of the research concentrating on the evaluation of benefits associated with increasing safety and reliability of the railway infrastructure. Improvement of safety and reliability is anticipated in particular by the implementation of suitable safety systems into the railway infrastructure to prevent the occurrence of incidents. The research outputs presented in this paper are mainly focused on the evaluation of economic impacts of the incidents. The research is based on the analysis of the database of incidents (RIA, 2018) provided for the purpose of the research by the Railway 
Infrastructure Administration (SŽDC), within which the incidents registered for the period 2011-2018 are divided into various sub-categories. Within the framework of the paper, the number of relevant categories is reduced solely to those categories of incidents which occur on the railway infrastructure and for which it can be assumed that they can possibly be prevented by previous implementation of suitable track or station signalling systems. The research does not take into the account the accidents at the level crossings.

\section{Present State References}

The research can be based on the conclusions of a number of scientific and scholarly texts. A key basis for assessing the economic efficiency of investment projects in the public sector is the Guide to Cost-Benefit Analysis of Investment Projects (Sartori, 2014), published by the European Commission in 2014, which includes general rules for economic evaluation of public investment projects as well as framework methodologies for economic evaluation of public investment projects in particular areas of public investment; for these areas are also presented illustrative case studies. National methodology for evaluating the efficiency of investment projects in the area of transport infrastructure, called the Departmental Methodology (MoT CZ, 2017) is based on this methodology. The Departmental Methodology is focused primarily on assessing the financial and economic efficiency as well as risks of investment projects in transport infrastructure in the specific conditions of the Czech Republic. The issue of evaluation of impacts of incidents has not been dealt with in more detail in scientific literature, however,

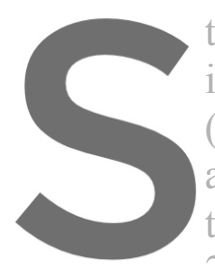
topics related to it definitely form the sybject of the research. The issue of the relationship incidents and human factor is dealt with in the research of (Bayse (Madigan, Golightly, addressed in the Swedish study (Forsberg, 2016) the railway infrastructure are the subject of the 2018) and (Read, Lenné, Moss, 2012). Latent and active errors leading to railway incidents are dealt with in the paper by (Zhou, Lei, 2018)

Register for free at https//wWw.scipedia.com to download the version without the watermark

\section{Methodology}

The subject of the research presented in this paper is to define methodological steps for evaluating the impacts of incidents on the railway infrastructure.

In particular, the following data from the information provided by the "Incident Statistics" (RIA, 2018) is considered within the research project:

- Impact on health

○ Death,

○ Serious injury,

- Minor injury,

- Material damage,

- Costs,

- Number of delayed passenger trains,

- Total delay of passenger trains,

- Number of delayed freight trains,

- Total delay of freight trains,

- Cause of incident emergence 

- Technical,
- Human factor,
O Others.

This paper evaluates especially the following characteristics of incidents:

○ Impacts on health,

- Delay of passenger trains; and

○ Delay of freight trains.

\subsection{Impacts on Health}

Incident impacts on health are based on the average number of casualties (dead, injured) and the unit cost associated with death, serious or minor injuries. Unit costs associated with traffic accidents are taken from the Departmental methodology of the Ministry of Transport and are described in more detail in Table 1.

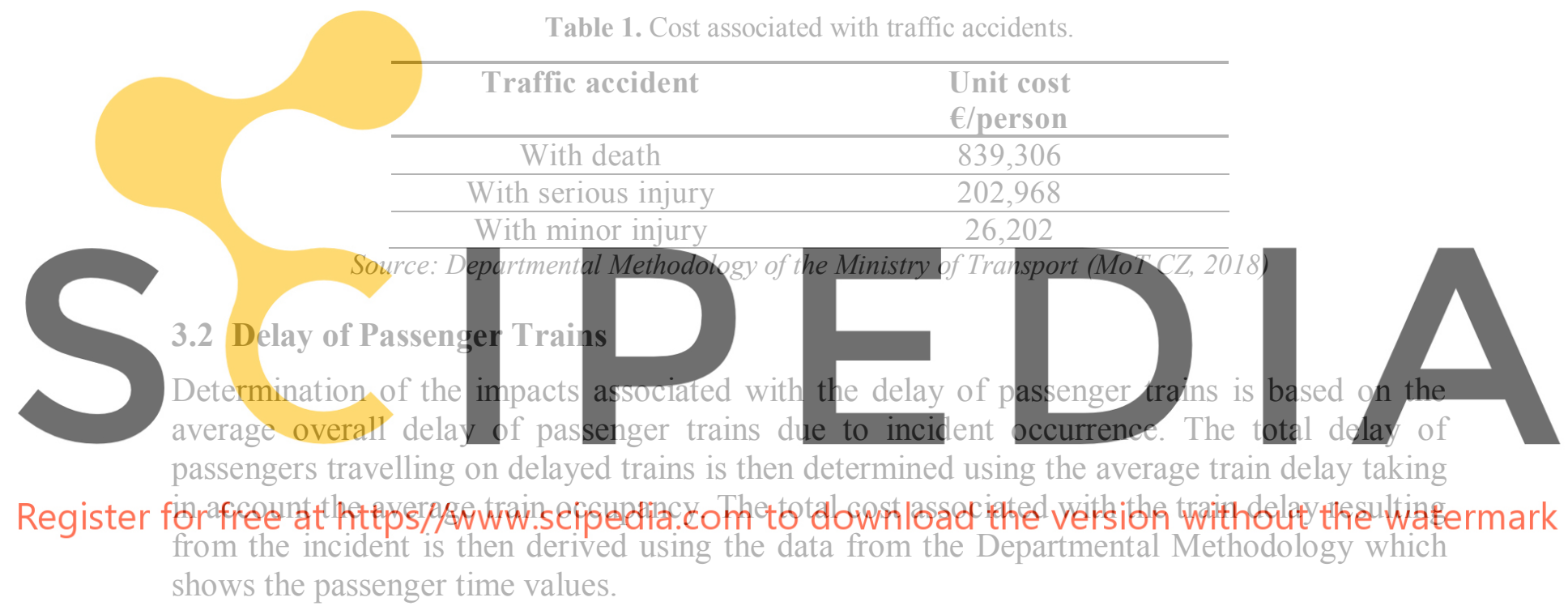

The average train occupancy for the whole railway network was determined using the data from the Czech Railways Statistical Yearbook of 2018 (CRG, 2018). In particular, information on the total transport performance of 2018 (assumed at 8,224.9 passenger-kilometres) and on the running of passenger trains for 2018 (123,596 train-kilometres in total) were used. The resulting average train occupancy for the entire railway network was set at 66.55 persons per train based on the above-mentioned data.

For the subsequent research, planned refinement of the average train occupancy calculation in terms of the division of the railway network into national and regional lines has been planned; where the national train lines are expected to have a higher average train occupancy than the regional train lines.

Passenger time values are taken from the Departmental Methodology and are shown in Table 2. 
Table 2. Time values of passengers on the railway infrastructure.

\begin{tabular}{llr}
\hline Passenger transport & & $\boldsymbol{€}$ /person-hour \\
\hline Working time & & 24.21 \\
\hline \multirow{4}{*}{ Non-working time } & Short transport & 9.43 \\
\cline { 2 - 3 } & Long transport & 12.11 \\
\cline { 2 - 3 } & Other - short distance & 7.91 \\
\cline { 2 - 3 } & Other - long distance & 10.14 \\
\hline
\end{tabular}

Source: Departmental Methodology of the Ministry of Transport (MoT CZ, 2018)

In accordance with the Departmental Methodology, it is generally assumed that in the case of non-working time, the ratio between commuting and other transport is balanced. Likewise, it is assumed that the ratio between long and short transport is also balanced. The ratio between business travel and non-business travel is considered to be 10/90. Based on the information provided, the average value of the passengers' time can be estimated at $€ 11.33$ /person-hours. This value was taken in the account in the case study. In the follow-up research, it is possible to focus on a more precise ratio between the individual reasons for transport (commuting, other), depending on whether the transport is situated on the regional or national line.

\subsection{Delay of Freight Trains}

The determination of the impacts associated with the delay of freight trains is based on the average overall delay

delay of a freight train, considering the average the Departmental Method with the train delay due The average weight of freight carried by train
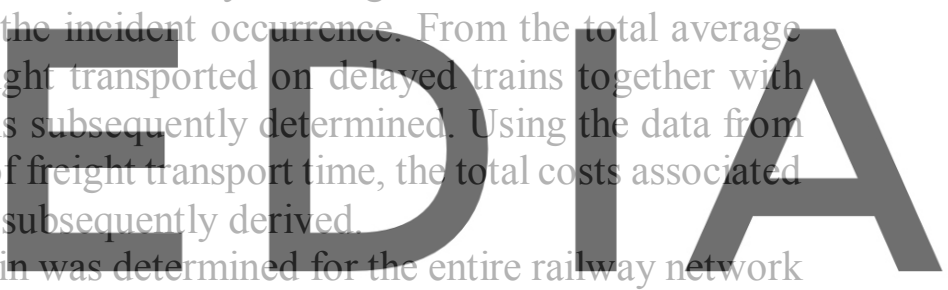
using data from the Statistical Yearbook of the Czech Railways Group in 2018 (CRG, 2018).

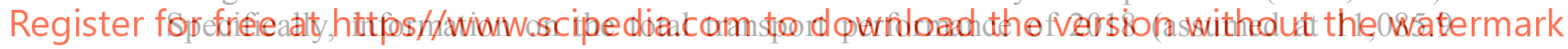
million tkm (tariff tonne-kilometres) and on the running of freight trains also for 2018 (a total of 24,348 million train-kilometres) was used. The resulting average train freight weight for the whole rail network in relation to this data was set at 455 tonnes/train.

The values of freight transport time have been taken from the Departmental Methodology and are given in Table 3 .

Table 3. Time values of freight traffic on the railway route.

\begin{tabular}{lr}
\hline Commodity & $\boldsymbol{€} /$ tonne-hour \\
\hline Commodities with low added value & 0.013 \\
\hline Normal cargo & 0.248 \\
\hline Commodities with high added value & 0.742 \\
\hline \multicolumn{2}{c}{ Source: Departmental Methodology of the Ministry of Transport (MoT CZ, 2018) }
\end{tabular}

The percentage representation of the above-mentioned commodities can be derived from information on freight transport by commodity groups of goods from the Statistical Yearbook of the Czech Railways Group from 2018 (CRG, 2018, p. 8). Total weights of goods transported by individual commodity in 2018 are shown in Table 4. 
Table 4. Freight transport by commodities in 2018.

\begin{tabular}{lr}
\hline Commodity & ths. tonnes \\
\hline Iron and engineering products & $7,979.7$ \\
\hline Construction material & $7,569.2$ \\
\hline Lignite & $6,637.1$ \\
\hline Black coal and coke & $7,352.9$ \\
\hline Other building materials and ceramics & $2,470.9$ \\
\hline Chemical products and liquid fuels & $4,764.6$ \\
\hline Wood and paper products & $4,733.2$ \\
\hline Food and agricultural products & $1,454.6$ \\
\hline Combined transport & 571.8 \\
\hline Automotive & $1,589.6$ \\
\hline
\end{tabular}

Source: (CRG, 2018)

By assigning the commodities listed in Table 4 to one of the following groups:

- Commodities with low added value (e.g. bulk substrates),

- Normal cargo,

- Commodities with high added value (perishable goods by means of transport),

it is possible to determine the average share of the listed categories of commodities on the transport performance and thus the average value of the freight time in case of a freight train delay. The average value of freight transport time value was set at $€ 0.246 /$ tonne-hour.

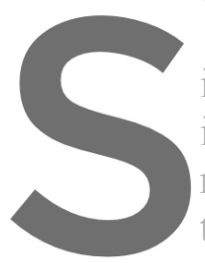

The quantities stated

impact of an incident o

in connection with the

railway station or the ra

those incidents resulting from a human factor
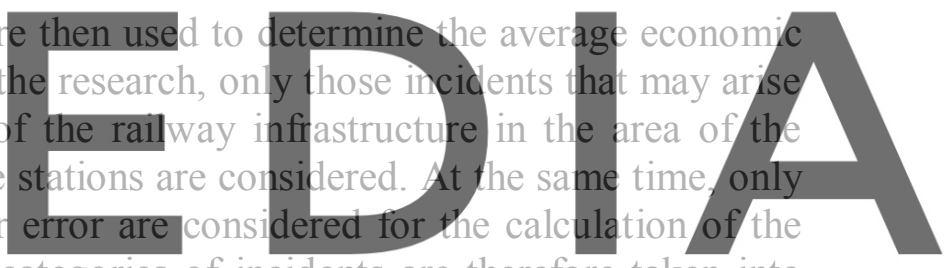

average impacts of incidents. The following categories of incidents are therefore taken into

Register for aree at https scale damage,

A2 Derailment of a rail vehicle resulting in death or injury to at least 5 persons or largescale damage,

A3 Collision of a rail vehicle with an obstacle in the passage resulting in death or injury to at least 5 persons or large-scale damage,

B1 Collision of railway vehicles resulting in consequences minor than in a serious accident,

B2 Derailment of a rail vehicle resulting in consequences minor than in a serious accident,

B3 Collision of a rail vehicle with an obstacle in the passage resulting in consequences minor than in a serious accident,

$\mathrm{C} 1$ Collision of railway vehicles resulting in consequences minor than in a serious accident or accident

C2 Derailment of a rail vehicle resulting in consequences minor than in a serious accident or accident,

C3 Collision of a rail vehicle with an obstacle in the passage resulting in consequences minor than in a serious accident or accident,

C6 Unauthorized movement of the rail vehicle behind a signalling device prohibiting 
driving resulting in consequences minor than in an accident,

C12 Unsecured movement of a rail vehicle resulting in consequences minor than in an accident,

C16Failure of signalling systems resulting in consequences minor than in an accident,

C19Unspecified incident, arising in connection with the movement of the rail vehicle resulting in consequences minor than in an accident.

\section{Results}

Interim research results can be presented on a case study. The case study includes the determination of the average impact of an incident of a defined category on the railway infrastructure. The basic characteristics of the assessed incident are as follows:

Category:

Number of incidents included in the analysis:

Nature of the cause:

Average number of deaths:

Average number of seriously injured:

Average number of minor injured:

Average delay of passenger trains:

Average delay of freight trains:

Average financial in

Average occupancy

Average freight weig

Table 5 contains the can
A1 Collision of railway vehicles resulting in death or injury to at least 5 persons or large-scale damage

15

human factor

0.2

0.33

3.8

$941.82 \mathrm{~min}$. (15.70 hours)

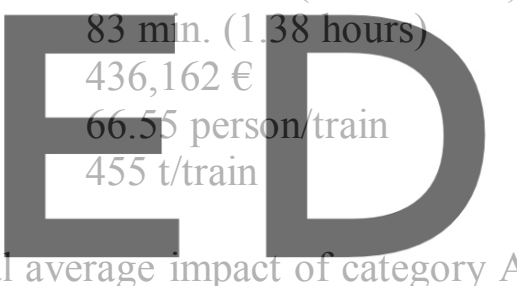

for the calculation are taken from the methodology chapter.

Register for free at https//WwW.scipedia.com to download the version without the watermark

Table 5. Average impact of category A1 emergency.

The nature of the incident

Unit impact Number of units Impact per item

impact

\begin{tabular}{lrrr}
\hline Killed persons & $839,306 € /$ pers. & 0.20 pers. & $167,661.29$ \\
\hline Seriously injured persons & $202,968 € /$ pers. & 0.33 pers. & $66,979.35$ \\
\hline Minor injured persons & $26,202 € /$ pers. & 3.80 pers. & $99,566.13$ \\
\hline Delay of passenger trains & $11.33 € /$ pershr. & $1,044.84$ pershr. & $11,834.50$ \\
\hline Delay of freight trains & $0.246 € /$ tonnehr. & 627.90 tonnehr. & 155.20 \\
\hline Financial impact at 2018 prices & $436,162 € /$ inc. & 1 inc. & 436,162 \\
\hline Total economic impact & & & $\mathbf{7 8 2 , 3 5 8 . 9 3}$ \\
\hline & Source: own elaboration & &
\end{tabular}

The case study shows the procedure for determining the average economic impact of an incident occurring on the railway infrastructure. It is evident from the results that the average economic impact of one A1 incident is $€ 782,358.93$. This procedure can be applied at other cases of incidents listed in the Methodology chapter. The subject of further research is supposed to be the calculation of the average economic impacts of other categories of incidents, this 
calculation will be further refined by dividing the railway infrastructure into regional or national lines, where the average economic impacts of incidents on a regional line may be different from those on the national lines especially with regard to train occupancy or the level of security on the railway line.

\section{Conclusions}

The paper has been elaborated within the research project focused on taking into account the benefits resulting from increasing safety and reliability of the railway infrastructure in the economic evaluation of railway infrastructure projects. Specifically, the paper deals with identification of methodology for the evaluation of impacts caused by the occurrence of incidents on the railway infrastructure. The evaluation methodology is based on common principles of economic analysis of public investment projects and is based on data provided by the Departmental Methodology and data from the database of incidents. The proposed methodology includes, in particular, impacts on the health or lives of casualties involved in an incident, impacts in the form of delays of passenger and freight trains and impacts in the form of material damage and costs. The proposed methodology has subsequently been verified on a case study of the category A1 emergency. Follow-up research is supposed to include also an evaluation of other incidents that may potentially arise in the context of a lack of security and which could be prevented by the possible prior implementation of the new security systems.

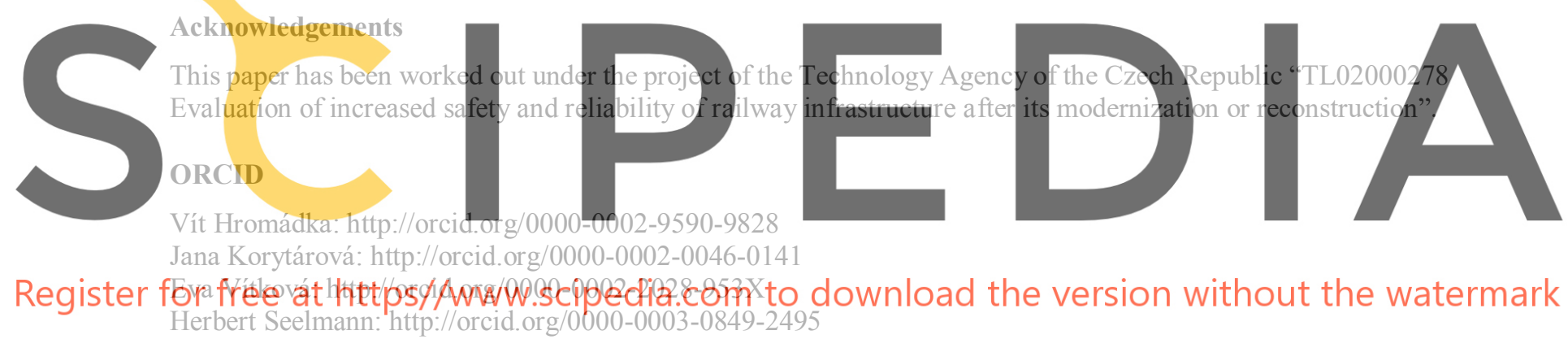

\section{References}

Baysari, M., Mcintosh, A. and Wilson, J. (2008). Understanding the human factors contribution to railway accidents and incidents in Australia. Accident Analysis and Prevention [online], Elsevier, 2008, 40(5), 17501757 [cit. 2019-02-18]. DOI: 10.1016/j.aap.2008.06.013. ISSN 0001-4575.

Czech Railways Group (CRG) (2018). Statistical Yearbook of the Czech Railways Group, 2018

Forsberg, R. (2016). Conditions affecting safety on the Swedish railway - Train drivers' experiences and perceptions. Safety Science, Volume 85, 2016, Pages 53-59, ISSN 0925-7535, https://doi.org/10.1016/j.ssci.2015.12.015.

Klockner, K. and Toft, Y. (2018). Railway accidents and incidents: Complex socio-technical system accident modelling comes of age. Safety Science [online]. Elsevier, 2018, 110, 59-66 [cit. 2019-02-18]. DOI: 10.1016/j.ssci.2017.11.022. ISSN 0925-7535.

Madigan, R., Golightly, D. and Madders, R. (2016). Application of Human Factors Analysis and Classification System (HFACS) to UK rail safety of the line incidents. Accident Analysis \& Prevention, Volume 97, 2016, Pages 122-131, ISSN 0001-4575, DOI: 10.1016/j.aap.2016.08.023.

Ministry of Transport of the Czech Republic (MoT CZ) (2017). Departmental Guideline for the Evaluation of Economic Effectiveness of Transport Construction Projects. 2017. Retrieved from http://www.sfdi.cz/pravidlametodiky-a-ceniky/metodiky/

Read, G. J. M., Lenné M. G. and Moss S. A. (2012). Associations between task, training and social environmental 
factors and error types involved in rail incidents and accidents. Accident Analysis \& Prevention, Volume 48, 2012, Pages 416-422, ISSN 00014575, DOI: 10.1016/j.aap.2012.02.014.

Railway Infrastructure Administration (RIA) (2018). Statistics of Occurences 2009 - 2018.

Sartori, D. (2014). Guide to Cost-benefit Analysis of Investment Projects, Economic appraisal tool for Cohesion Policy 2014-2020. European Commission, Directorate-General for Regional and Urban policy. 2014. ISBN 978-92-79-34796-2.

Zhou, J.-L. and Lei, Y. (2018). Paths between latent and active errors: Analysis of 407 railway accidents/incidents' causes in China. Safety Science, Volume 110, Part B, 2018, Pages 47-58, ISSN 0925-7535, DOI: 10.1016/j.ssci.2017.12.027.
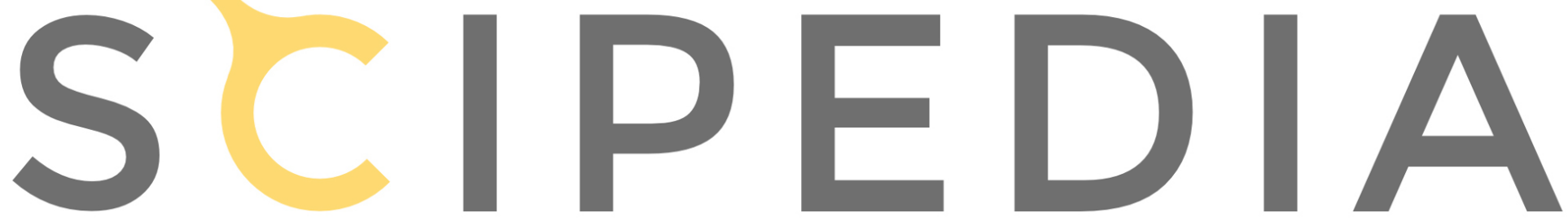

Register for free at https//www.scipedia.com to download the version without the watermark 